\title{
The Role of Teachers in Establishing an Attractive Environment to Develop the Creative Thinking among Basic Stage Students in the Schools of Tafilah Governorate According to their own Perspective
}

\author{
Ruba Al-Mahasneh ${ }^{1, *}$ \\ ${ }^{1}$ Faculty of Educational Sciences, Tafila Technical University, Jordan \\ *Correspondence: Faculty of Educational Sciences, Tafila Technical University, Jordan. Tel: 962-772-254-574. \\ E-mail: Mashhad33@gmail.com
}

Received: April 1, 2018

Accepted: April 19, 2018 Online Published: May 23, 2018

doi:10.5430/jct.v7n1p206

URL: https://doi.org/10.5430/jct.v7n1p206

\begin{abstract}
The objective of this study was to identify the role of teachers in founding an attractive environment for developing the creative thinking, among the students of the basic stage in the schools of Tafilah Governorate. The researcher applied the descriptive statistical method, and developed a questionnaire consisting of (45) items, divided into five Dimensions: "Teaching strategies, Material preparations, extracurricular activities, Personality traits and Evaluation strategies ". The instrument stability and validity were validated and approved. The sample of the study consisted of (300) female and male teachers, who were selected through a simple random method. The study resulted of the are the following:

- The estimate of the sample members of the instrument as a whole was moderate, and the fourth Dimension "personal traits" ranked first, with a moderate estimation, while the second was "material preparations" which came in the last rank, and with a low grade of estimation.

- There were statistically significant differences in the sample of the study teachers' same role, attributed to the variables of "gender and academic qualification", while there were no statistically significant differences in the sample of the study for their role attributed to the variable of "years of experience".

Based on the results of the study, the researcher presented recommendations, including reviewing the programs of preparing and training teachers, the need to include plans and strategies for the development of creative thinking, and enrichment of the school curriculum for the basic stage programs to develop the creative thinking.
\end{abstract}

Keywords: teachers, creative thinking, students

\section{Introduction}

The educational systems strive to achieve the goals and objectives of their societies, since the future will only be for nations that invest its young people talents greatly, stimulate their rational thinking and productive interaction with their environment; to prepare the productive individual in the society. The new and unprecedented educational problems of globalization, have led education systems to take new forms of their contents and aspects, where lifelong learning has become a necessary requirement.

Traditional education systems are no longer sufficient for community development and rehabilitation, since students' thinking must be elevated to the highest levels that can help them to realize the mind, and use it to overcome the problems they encounter.

Ranko (2012) suggests that thinking is a series of mental activities performed by the brain in response to the millions of visual and invisible stimuli it receives through the five senses. It is a search for a meaning that needs meditation, focus on task, and the experience acquired by the individual. Education experts agree that every student has some creative thinking, and that thinking does not occur in isolation from the content. Robinson (2009) suggests that establishing the creative mental capacity is only the outcome of the interaction of a number of variables: such as school curricula and environment, sources of education, teaching methods, evaluation strategies, and extracurricular activities. 
These activities require the teacher, who shows his role, to encourage students to self-learning, developing the skills of creative thinking and communication as well as the positive debate, leadership, initiative, desire for teamwork, belonging, increasing their awareness of the importance of time, and developing an emotional and social class atmosphere that achieves the principle of effectiveness and openness to world events with a close vision of satellite transmission under the umbrella of globalization. (Nour, 2015)

Development of creative thinking among students is a fundamental goal falls within the emotional sphere. It is a religious requirement before it is a global educational necessity. Teachers recognize the characteristics of their students and needs which they build upon it their teaching strategies and create a safe and supportive classroom environment, based on the art of receptiveness to them, and strong social relationships that drive them to self-learning, through using the resources provided by the technology knowledge. (Abu Jado and Nofal, 2007).

The most important feature of creative thinking is novelty and complexity. It reflects multifaceted phenomena and is also characterized by flexibility, fluency, amplification and sensitivity to problems (Mostafa, 2011). One of the most important assumptions is that creativity is the right of everyone, not only the category of creative individuals, a skill that anyone who has the willingness to learn, although individuals may vary in this readiness if the environment is available to him; To the children (Chin, 2013). Jarwan (2013) indicated several intellectual perspectives towards the creative thinking. Simpson suggests that it is the initiative as an individual's ability to get rid of the normal context and follow new patterns of thinking. Rogers emphasizes the element of novelty so it is the process of emergence of new production as a result of the interaction of the individual with the environment

Alotoum et al (2007) indicated the Freudian philosophy towards creative thinking as an "Escalation of feelings to the pent-up individual who can not satisfy. Sa'adah (2003) also referred to the definition of Guilford as an open form in which the production is characterized with variety of answers not restricted to input. Alsorour (2002) pointed out the definition of creative thinking by Torrance as a "process in which the person becomes sensitive to problems, recognizes gaps and information, looks for evidence of knowledge, sets hypotheses and validates them, and makes adjustments to the results."

Creative thinking is a complex mental activity, which requires the search for solutions or alternatives to achieve new production, besides the disclosure of mysterious and unfamiliar phenomena to make them familiar, as well as to overcome the usual stereotypes of the pattern, and to turn the idea in several ways and enrich it with additional and profound information.Nour (2015) suggests that there are many factors that hinder the creative thinking, such as the lack of trust, familiarity, excessive enthusiasm, saturation, stereotypical thinking, and feelings of helplessness. Factors also include the inability of individual to maintain the balance between competition and cooperation, and simulation, control, and methods of education that rely on indoctrination that does not help them practice free thinking.

Debono Center for the Teaching of Thinking, (2015), suggests that the creative process goes through five consecutive stages, the first stage consists of preparation: the problem is identified, where sufficient and accurate information is gathered about all its elements.; the second stage consists of fermentation: a hidden activity that individual lets problem to be condensed in his mind and go to another activity; the third one focuses on the enlightenment: it is a spark that triggers the individual's thought to illuminate the solution. It is sudden, and the individual sticks to it because it may not come back again. (Nour, 2015); while the fourth stage is the accomplishment: the stage of testing and confirming the solution (Robinson, 2009); and the last one consists of Collective innovative thinking: It is one of the methods used by governments, institutions to find appropriate solutions to different problems and to produce new ideas using brainstorming strategy.

Alshalti (2010) emphasizes the role of teachers in providing enrichment programs to meet the needs of their students in various dimensions of knowledge, skills and emotion. This enables them to work innovatively with a high degree of intelligence, self-motivation, and a sense of freedom and security that allows debate and dialogue. This is what Rogers called for (in Qasim, 2014), that the careful teacher should be keen to provide two basic conditions in the classroom that are: reassures psychological tranquility and psychological freedom, where the first is achieved by minimizing evaluation and criticism, with teacher understanding of positions that restore student validity in his/her booming abilities.

The Human Development Report (in Abu Alsaud (2010)), under the title of "Human Capacity Building: Education", indicates the teacher's role as a hub of innovation work, a guide to sources of knowledge and learning, coordinator of the learning processes, and debugger of learning errors, a rectifier of learning outcomes, and an advisor to the appropriate capabilities and attitudes of learner. Roney (2000) suggests that creativity, flexibility, adaptation, enthusiasm, communication skills, patience and honesty are among the most important characteristics of active 
middle stage teachers. Yagoob. (2012) indicate that the necessary features of teacher are: friendly open-minded and receptive to students, a listener to them, who understands their needs and abilities, who encourages them and keen to establish a fun classroom environment. Features also include that teacher teaches them kindly and uses various and thought-provoking methods, possesses communication skills, familiar with the material he teaches, serious in job, and invests it in learning time.

The teaching process, as a contemplative and critical process requires a teacher who has an entrepreneurial spirit, an educational researcher, who seeks to experiment and innovate, has the necessary skill to solve educational problems, as well as he has modern educational strategies based on classroom and extracurricular activities that defies the imagination of learners, and their minds with his intellectual creative variations (Qatami 2012; Nour, 2015). The teaching process is characterized by constant change since there are no rigid teaching forms suitable for all students; therefore the teacher is responsible for designing authentic learning situations rich of educational materials that develop the higher skills of the mind such as induction, reasoning, analysis and judgment (Al-Nafie'i, 2010).

Abdulhaq\&Alojaili (2015) indicate the possibility of developing innovative thinking using teaching concerned with the learner positivity and his participation in the educational process, through the implementation of multiple activities, and emphasize that there is a significant correlation between imagination and innovation. The use of science fiction stimulates greatly the imagination and creativity, develops fluency, flexibility and authenticity of students. Jarwan (2013) suggests that model learning and enhancement together contribute significantly to developing the creative thinking. It is important for the teacher to encourage the active learning that exceeds the limits of sitting and negative listening to apply the notes, comparison, classification and problem solving; and focuses on active discussion as a way to stimulate thinking, and interest in the application of self-learning.

Salloum (2014) suggests that an attractive environment for creativity requires multiple educational activities such as physical, cultural, social and artistic activities, as well as dimension trips and projects that provide students with creative thinking skills. Qatami (2012) emphasizes the need for free of classroom controls, and the simulation of nature in a broad manner, in order to achieve the integrated development of the learner personality for physical, mental, cognitive, social, moral and psychological aspects, provided that such activities are consistent with and complementary to the school program. One of the world's most advanced technologies, which Edward Bono (DeBono Center for Thinking Education, 2015) called for, is the Six Hats strategy.

Hecerian (2004) considered it an effective system that helps guide thinking paths and frees the mind from its stereotyping and monotony. This method divides the thinking into six patterns, where each style is a hat worn or taken off by the human upon the way he thinks at that moment. This method gives the individual a great ability to be superior and successful in educational and personal situations, where it turns the rigid attitude into creative situations, in which man needs different colors of thinking. Therefore, he needs to wear several different hats for thinking, creativity and criticism Khadr (2015) points out that it has an impact on developing creative thinking skills: fluency, flexibility, authenticity and decision-making, as well as its effectiveness in increasing student achievement at all levels of study.

One of the collective methods of training on creative thinking is the brainstorming method which was created by Osborn (2009), (referred to Robinson,2009). It aims to encourage authenticity, flexibility, and thoughtfulness, and to stimulate students to put forward many ideas and solutions to the single problem. It also allows the teacher to follow up the flow of ideas and methods of implementing them in the minds of students, thus satisfy the need of creative people to explore, research and investigation as well as it develops the ability to visualize and think about many possibilities through a safe environment method of Synectics which was created by Gordon. It also allows the teacher to follow up the flow of ideas and methods of implementing them in the minds of students, thus satisfy the need of creative people to explore, research and investigation as well as it develops the ability to visualize and think about many possibilities through a safe environment method of Synectics which was created by Gordon.

This method changes the strange into familiar through understanding and analyzing the problem, then making the familiar as strange, which means dealing with the problem and a new approach to reach a new theory. (DeBono Center for Thinking Education, 2015)

Alazzam (2017) points out that the learning process is based on several dimensions: What should students learn? How do they learn? How do you measure the progress they make? Therefore, it is necessary to use objective, scientific and honest criteria to provide a clear picture of the student's performance and ability to apply what he knows. 
This can only be done through the written tests of "pen and paper" which neglects the student's role and allows him one chance of success since it focuses only on retrieving information stored in the memory without regard to whether or not learning is meaningful, and alternative assessment, or realistic assessment as an alternative to the traditional assessment method. Ali (2011) argues that alternative assessment stimulates students' exercise of mental processes, the skills of exploration, discovery and creativity, which require that the problems, tasks or work involved in the study are realistic and relevant to the daily life of the student; besides that it enhances several forms of collaboration among the students. The collaborative learning provides better chance for learning and lets them avoid the comparisons based on the collective criteria of performance that have no place in the alternative assessment.

Several researchers call the teachers to apply the performance-based assessment for its implied strategies and instruments such as: written and verbal tests, tests of performance, orientation tests, personal attitudes, student portfolio, because students need to apply their learning skills in real life situations that help them control the problems. (Altarawneh (2011), AbouShairah et al(2010) Albasheer \& Essam(2011). Oudah (2010) suggests that the current assessment is still subject to a linear sequential system that represents: educational objectives followed by the implementation of the educational process, then judgment of the educational process success or failure. This system lacks the property of self-correction or feedback which requires reviewing the methods of student evaluation, with an interest in evaluation as a cybernetic system, which depends on mutual interaction among elements of the learning system, including the assessment itself.

Material resources are a strong pillar, a positive side in improving the process of teaching and learning, and it is an important stimulus in developing skills and driving the creative process.

Abu Shamaleh (2013) recommends allocating a budget for classroom and extracurricular activities that foster innovation. Ma'alouli (2010) also states that the availability of audiovisual and printed educational materials and equipment, in addition to blackboards, models, tapes, films, transparencies, magazines, books, maps, and laboratories, through which practical skills and experiences are integrated into the teaching and evaluation processes, and play a prominent role in motivating learners to discover, create, and explore their creative talents in various dimensions. Based on the above, the researcher believes that an educated and creative generation must be built based on creativity and innovation, and the ability to solve problems to meet the objective, realistic, as well as professional, social and psychological challenges that arise in the challenge of competing in a long-term race towards self-affirmation, and to contribute effectively to human civilization

This is not possible without establishing the workshops and laboratories in schools. The learner is accustomed to like experimentation, technique, apply theories and stimulate imagination. It represents the philosophy of contest, challenge and invention, thus acquiring creative behavior based on the values of lifelong learning that help feel ability for productivity and addition to the present and future of society.

The researcher reviewed the previous studies related to the subject of this research where the following is a presentation of these studies Barakat and Abdul-Jabbar (2017), study aimed to determine the impact of teaching Arabic language by using cloud computing technology in developing the self-learning and creative thinking skills of the third grade students in private schools in Jordan. In order to achieve the objectives of the study, the semi-experimental approach was adopted in the application of cloud computing technology to the random sample members of 50 female and male students who were selected from Mashreq International Private Schools. The number of students was divided into two groups, (22) for the experimental group, and 28 for the the control group. The experimental group was chosen to study the Arabic language for the third grade through cloud computing, while the control group studied the subject by traditional regular program. The researcher built a measure of creative thinking and another one for self-learning skills. The results of the study showed that there were statistically significant differences attributed to cloud computing strategy. The differences were in favor of the experimental group in the self-learning and creative thinking scale.

Jahjah( 2016) study sought to reveal the impact of the six hats method in developing creative thinking skills (fluency, flexibility, authenticity, total creativity); decision making skills (problem identification, alternative generation, choice of the best alternative); the achievement of social science (lower level, higher level) by the third grade students. Of the third grade students. The research adopted a semi-experimental approach based on the choice of experimental and control group. The sample consisted of (52) students from the school of JafarSadiq II. The researcher used the Torrance test for creative thinking, the image of words, (a), and prepared a test for decision-making, and another test for achievement. The results of the study showed statistically significant differences between the experimental group and the control group in the skills of creative thinking (fluency, 
flexibility, originality, total creativity), decision making skills (problem identification, generation of alternatives, selection of the best alternative) Upper), and for the favor of the experimental group

Alswaiti (2015) studied the role of the school administration in the development of creativity in public schools in Hebron and Bethlehem governorates from the principals viewpoint in the light of the variables (gender, academic qualification, years of experience, specialization and workplace). The study included (196) female and male principals. The researcher adopted the descriptive approach, and also prepared a questionnaire consisting of (39) questions. The study found that the development of creativity was very large in the dimensions of "teacher, school administration, community, school environment", while the educational curricula in the development of creativity were moderate.

Alqarar'ah study(2014) examined the impact of brainstorming in the teaching of science on the development of creative thinking among the $7^{\text {th }}$ grade students in Jordan. The sample of the study was selected according to the logical method where its size was 76 students in the $7^{\text {th }}$ grade of the schools in Tafila. The sample was randomly divided into two groups: an experimental group studied through brainstorming method, while a control group studied through the traditional way. Both groups studied the same content. The study lasted for seven weeks. The Torrance Scale for Creative Thinking was used as a modified image of the Jordanian environment. The validity and consistency of the measure in this study were confirmed. The results indicated an impact of the method of brainstorming on the development of creative thinking in general and on the development of the skills of fluency, flexibility and authenticity among the $7^{\text {th }}$ grade students. In the light of the results, some recommendations were made, including encouraging science teachers to use brainstorming method Science.

Alaga (2014) aimed at investigating the role of secondary education institutions in developing the creativity among its students, and proposing a perception to empower that role. The study consisted of five areas (the role of the school administration, the teachers, the curriculum, the school environment, the community and the family). The study sample consisted of (741) male and female students. The results found that the most important factors contributing to the development of the effectiveness of the role of secondary education institutions in the development of creativity among students were: curriculum, teachers, community and family, school administration, school environment, respectively

Abu Shamaleh (2013) aimed to identify the degree of practice by the school principals for their role in the development of creativity among the teachers of public education in Gaza governorates from their point of view and its relationship with some variables. The researcher adopted the analytical descriptive method and developed a questionnaire that included 40 items and applied them to a random sample of (228) female and male teachers in public education schools. The results also indicated that there were statistically significant differences in the degree of the school administration's role in the development of creativity among teachers of public education attributed to the gender variable (male, female) and for the favor of females teachers, but there were no statistically significant differences attributed to number of years of service. In the light of the results, the researcher recommended activating the role of the school administration in developing the creativity of the teachers of public education and allocating a budget for the extracurricular activities that develop the creativity.

Khayo (2013) studied the role of the teacher and his competencies in the $21^{\text {st }}$ century from the viewpoint of the academic members of the Faculty of Education - University of Damascus. A questionnaire was used as the study instrument for the sample of 49 individuals. The results indicated that the $9^{\text {th }}$ role of the "ability of equality and solidarity" ranked first, and the $7^{\text {th }}$ role "the ability to treat students as real partners" in the last place. The results also indicated no statistically significant differences in the views of faculty members regarding the importance of teacher roles and competencies in the $21^{\text {st }}$ century attributed to the variables: gender, experience, degree, in each role of the teacher. and his competencies in the twenty-first century attributed to the variables: gender, experience, degree, in each role of the teacher. In the light of the results suggested the researcher to adopt a list of roles of the teacher, and competencies in the twenty-first century in educational rehabilitation programs

Mansour (2013) aimed to identify the role of the educational staff in developing creative thinking skills among the children of kindergartens from the point of view of teachers according to variables (years of experience, qualification, subject to training courses). The researcher developed a questionnaire as the instrument to test the hypotheses of the study. The sample consisted of (60) teachers who were randomly selected from the Kindergartens that apply the Educational Staff System to the Directorate of Education in Damascus. The results indicated no statistically significant differences in the viewpoints of teachers about the role of basic educational staff in developing creative thinking among the kindergartens children attributed to the years of experience of the teachers, while there were statistically significant differences attributed to the variables (scientific qualification, and subject to training courses.) 
Alassaf (2013) aimed at determining the attitudes of social studies teachers towards developing creative thinking skills among the students of the upper elementary stage in the $3^{\text {rd }}$ Education Directorate of Amman, and its relation to the variables of: the scientific qualification and experience. A random sample of 133 teachers was selected. The study instrument consisted of (45) items divided into three dimensions: teachers' attitudes towards (developing creative thinking abilities, identifying creative skills, encouraging and adopting creativity. The results indicated that the attitudes of teachers, toward developing creative thinking skills among students, were positive with significant differences in these attitudes of teachers toward attributed to the academic qualification and for the favor of the postgraduate certificate holders, with no statistically significant differences in teacher attitudes were attributed to the experience variables and years of service.

Tawalbah (2012) aimed to reveal the difference between the teachers' awareness of the extent of their self-efficacy in developing their students' creativity and awareness. A questionnaire was prepared for this purpose, which included (48) verifiable and validated items. A sample consisted of (48) male teachers, (34) female teachers, (89) male students and 91 female students of $9^{\text {th }}$ and $10^{\text {th }}$ grades in the city of Zarqa - Jordan. The results indicated that male and female teachers estimated their self-efficacy level in the development of creativity, with an average of (130.37) versus 116.71 for students in the moderate category, for the favor of teachers, and there was a statistically significant difference between male teachers and their students, while there was no difference between female teachers and their students.

Alshalti (2010) aimed at recognizing the school environment system and its impact on developing the creative values of contemporary fine art among secondary school female students. The study used the descriptive approach, while its sample consisted of (51) female teachers of fine arts education for the secondary stage in Jeddah - Saudi Arabia for the first semester 2010/2011. They were selected in the simple random way. The study instrument consisted of (64) items. The study found that statistically significant differences among the means of the school role, the role of curriculum elements, and the role of educational activities in the development of creative values. It also indicated that no statistically significant differences among the means of the role of female teacher in developing the creative values in terms of fine arts education from their point of view according to the variables: number of years of service, specialization and training courses.

Albelushi (2010), aimed at revealing how Islamic education teachers practice the methods of developing creative thinking skills in the classroom of $8^{\text {th }}$ and $9^{\text {th }}$ grades, and showing the effect of gender, experience and skill variables on the degree of practice. The study instrument (observation card), which consisted of (33) items, was distributed to them on four skills of developing creative thinking. The results found that the degree of Islamic education teachers practicing methods was moderate. There were statistically significant differences in the practice to the favor of female teachers in the skills of authenticity and focus, with no differences in the skills of fluency and flexibility attributed to the experience. In the light of the results, the study recommended that the teacher education programs in the higher education institutions should include strategies for the development of creative thinking, and teacher evaluation through items for evaluating the skills of developing creative thinking, strengthening the Islamic education curriculum with creative training activities, problems that challenge students' thinking, Through which they can develop creative thinking skills.

Olayan (2010) aimed at identifying the relationship between the characteristics of the teacher and innovative activities as perceived by students of the basic stage. The researcher used two instruments: Torrance's list of innovative activities "Arabized by MajdiHabib", and a questionnaire to measure the characteristics of the teacher as perceived by the student. The results showed that the characteristics of the teacher were high, while the highest level was for the mental cognitive characteristics, followed by practical characteristics of teaching, personal characteristics, whewre as the last ranked were social characteristics, "dealing with students". The results showed that the innovative activities of students in the basic stage were weak and below the average.

Diab (2005) aimed to identify the obstacles against the development of creativity and thinking among the students of the basic stage in Gaza Strip schools related to the curriculum, the school environment, the teacher and the student, as well as identifying the methods to reduce them. The study sample consisted of (100)female and male teachers, randomly selected from ten male and female schools in Gaza City. The researcher prepared a questionnaire consisting of four dimensions: obstacles related to the curriculum, the school environment, the teacher and the student. The results showed that one of the most important obstacles against the development of thinking were: overcrowded classrooms, lack of opportunity for students to undertake innovative activities that develop their abilities and gain creative thinking skills: authenticity, fluency, flexibility and judgment, and understanding the relationships through which students can produce creative production which is characterized by quality and authenticity. 
Through the review of previous studies, we can notice the teacher's important role in the development of creative thinking among students in the various academic topics, and all stages of education, his need to use programs and enrichment activities, and the educational basis to stimulate creativity, besides identifying the obstacles against creative thinking, and identify ways to reduce them.

This study utilized from these studies regarding theoretical literature, data collection instruments and statistical methods of processing. This study is characterized in that it is the first one - within the limits of the researcher's knowledge - that dealt with the role of the teacher in creating an attractive environment for the development of creative thinking among the students of the basic stage in the schools of Tafila governorate

\section{Study Problem and Questions}

Despite the voices that call for attractive school environment towards creativity, and the need to enhance the concept of students creativity, by the teacher to produce new concepts, but the real situation indicates a weak role of educational and non-educational institutions in the development and promotion of the creativity culture among students, or to prepare them to face the obscure future, but only to teach them some rigid skills and knowledge, which, although useful in today's world, will not necessarily be in the future, so we must take creative thinking to the forefront in educational research in the $21^{\text {st }}$ century, because the investment of creative thinking skills became the obsession of human societies to achieve progress and development and well-being.

Through the dimension work the researcher found that there is a gap between the formal curriculum and the realistic curriculum as a result of the deviation of the strategies of implementation of the curriculum on the planned track despite the efforts of the Jordanian Ministry of Education, to raise the minds of students and investment of human resources to the maximum capacity,

The pillars of the Education Reform for the Knowledge Economy (ERfKE) project are to improve all aspects of the learning process, including the preparation and rehabilitation of the teacher, and to provide him with modern assessment strategies designed to develop the thinking, the creation of a nurturing environment that sponsors the student and provides him with modern methods(Ministry of Education, Jordan, 2010).

Hence, this study aims to find the role of teachers in creating an attractive environment for the development of creative thinking among the students of the basic stage in the schools of Tafilah, from their own point of view, by answering the following questions:

1. What is the role of teachers in creating an attractive environment for the development of creative thinking among the students of the basic stage from their own point of view?

2. Is there a statistically significant difference at the level of significance of $\alpha \leq 0.05$ in the estimation of the study sample for the role of teachers in this sense attributed to gender, academic qualification, years of experience and interaction between them?

\section{Importance of the Study}

The importance of the current study stems from: the importance of the teacher's role, through providing the best methods of education that stimulate creativity, and meet the needs of the real learner, besides assisting officials and those involved in the educational process to plan and develop curricula, which helps in creating an environment conducive to the development of creative thinking among students, as well as

providing principals, teachers, the community and the family of their role in creating an attractive environment for developing students' creativity, along with providing the Education Faculties with feedback on this role of, which may help to develop teacher training programs and grow professionally., and the last was making results and recommendations of this study will raise some of the issues that require further studies related to creative thinking, especially that the research and educational studies that dealt with this phenomenon are very few.

\section{Terminology of the Study}

"Creative thinking": is a complex and purposeful mental activity directed by a strong desire to seek solutions or achieve authentic results that were previously unknown. Creative thinking is characterized by comprehensiveness and complexity. It is of higher level of complexity of thinking because it involves cognitive, emotional and moral elements that constitute a unique state of mind (Jarwan, 2012). The researcher suggests that creative thinking is characterized by the variety of responses produced and the ability to solve the problem in any situation exposed to the individual, which 
leads to production characterized by novelty, originality, fluency, flexibility, sensitivity to problems and characterized by modernity and non-typical. It is a unique thinking. The procedural definition of creative thinking refers to the degree to which the teacher obtains through answering the questions of the questionnaire.

- "Role": A model of practice, or expected behavior associated with a particular location in a particular society. The role of the teacher is a set of associated activities, behavioral patterns that achieve what members of the education profession and the environment and society expect it to do.

- "Basic stage": It is an educational stage of the educational system in Jordan, from 1st-10th grade.

\section{Study Limitations}

1. Human determinants: Teachers of the basic stage in the schools of Tafila governorate.

2. Time Limits: First Semester 2016/2017.

3. Spatial limit: Governerate of Tafila.

4. The study adopted the instrument developed by the researcher, consisting of (45) items, distributed over (5) Dimensions directly related to the role of teachers in creating an environment conducive to the development of creative thinking.

\section{Study Methodology}

The present study aimed at identifying the role of teachers in creating an attractive school environment for the development of creative thinking among the students of the basic stage in Tafileh governorate schools. Therefore, the descriptive method was used in the survey as the most suitable method for the nature of the study and its objectives.

\section{Population and Sample of the Study}

The study population consisted of all 870 female and male teachers in various disciplines of the basic stage in the governorate of Tafilah for the academic year 2016/2017. The study sample consisted of (300) female and male teachers. Table (1) shows the distribution of the sample according to the study variables.

Table 1. The Distribution of Sample According of the Variables of the Study

\begin{tabular}{cccccc}
\hline Gender & No. & Qualification & No & Experience & No \\
\hline male & 142 & $<$ bachelor & 179 & $<10$ years & 161 \\
Female & 158 & Bachelor or more & 121 & $>10$ years & 139 \\
Total & 300 & Total & 300 & Total & 300 \\
\hline
\end{tabular}

\section{Instrument of the Study}

To answer the study questions, the researcher developed the study instrument based on the relevant literature (Alazzam, 2017; Jahjah, 2016; Alswaiti, 2015; Olayan, 2010). The question was: What is the role of teachers in creating an attractive environment for the development of creative thinking among students in the basic stage?

After completing the teachers' answers, the researcher prepared (45) items divided into five Dimensions: "Teaching strategies, material settings, extracurricular activities, personal characteristics, and assessment strategies." The Likert 5 points Scale was applied ". Each item was given a scale of 5 points (1-5) five- (very high, high, moderate, low, very low), and the following weights were given: $1=$ very low and 5 =very high. The researcher determined the degree of arithmetic mean as follows: (According to the equation we have a five-step, so the length of the period $=$ $5-1 / 3=1.33$, and from it $(1+2.33=1.33$ as follows: (Oudah, 2010).

$1-2.33$ indicates that the score is low

2.34- 3.67 indicate that the score is moderate.

3.68 - 5 indicates that the degree is high.

\section{Validity of the study Instrument:}

In order to verify the validity of the study instrument, the researcher presented it to a group of 15 reviewers, (6) members of the teaching staff in the Department of Curriculum and Teaching at Tafilah Technical University, 5 
members at Mu'tah University, and (4) teachers of the basic stage. They were asked to make observations about the instrument in terms of: the relevance of the items to the subject of the study and its objectives, the language style, the comprehensiveness of the items and the suggestion of what they deem appropriate. In the light of this request, the researcher made rephrasing of some items to make the instrument in its final form

\section{Reliability of the study instrument:}

To verify the stability of the measuring instrument, the internal consistency coefficient of the study instrument was extracted using the Alpha-Chronbach equation. The coefficient of stability was 0.93 . The study instrument was also applied and re applied to a survey sample of 25 female and male teachers from outside where the stability coefficient was (0.88). These two values are suitable for the purposes of this study. Table (2) shows the values of the stability of the total instrument and its five sub-domains.

Table 2. The Reliability Coefficients of the Instrument for Each Dimension of Study and for the Instrument as a Whole

\begin{tabular}{ccccc}
\hline Dimension & Item & $\begin{array}{c}\text { No. of } \\
\text { Items }\end{array}$ & $\begin{array}{c}\text { Reliability } \\
\text { Coefficient }\end{array}$ & $\begin{array}{c}\text { Internal } \\
\text { Consistency } \\
\text { coefficient }\end{array}$ \\
\hline $\mathbf{1}$ & Teaching Strategies & 112 & 0.86 & 0.91 \\
$\mathbf{2}$ & Material Preparations & 66 & 0.81 & 0.87 \\
$\mathbf{3}$ & Extracurricular Activities & 112 & 0.86 & 0.89 \\
$\mathbf{4}$ & Personal Traits & 77 & 0.87 & 0.92 \\
$\mathbf{5}$ & Assessment Strategies & 88 & 0.84 & 0.90 \\
& Total stability of instrument & 445 & 0.88 & 0.93 \\
\hline
\end{tabular}

\section{Study Procedures:}

The following steps have been taken:

- Access educational literature on the role of teachers in creating an environment conducive to the development of creative thinking among students in the basic stage.

- Develop and prepare the study instrument in its initial form, then amend it after review.

- Verify the reliability and stability of the instrument.

- Identify the study population, select the sample members and continue through the application procedures.

- Distribution of the study instrument on the study sample.

- Collection, tabulation and classification of data, and organizing and presenting the results of the study.

- Discuss results and draw conclusions.

\section{Statistical Treatment Methods}

The Statistical Package for Social Sciences (SPSS) was used to answer the study questions through the use of appropriate statistical methods, as follows:

- To answer the first question, the arithmetic means, the standard deviations of each dimension and each item were calculated.

- To answer the second question: the researcher used Three-Way_ANOVA

\section{Study Variables}

First: Independent variables: It is used as follows:

- Gender: It has two levels (males, females).

- Years of experience: and has two levels (less than 10 years), (10 years and more).

- Academic qualification: It has two levels: (less than bachelor, bachelor and above).

Second: The dependent variable: The role of teachers in creating an attractive environment for the development of creative thinking among the students of the basic stage from their own point of view. 


\section{Study Results and Discussion}

Question 1: What is the role of teachers in creating an environment conducive to the development of creative thinking among students of the basic stage from their own point of view?

To answer this question, the arithmetic means and the standard deviations of the estimates of the sample were calculated on each of the study item, and the instrument as a whole, as shown in Table (3).

Table 3. The Arithmetic Means and the Standard Deviations of the Estimates of the Sample Members on Each Item of the Dimensions of Study and on the Instrument as a Whole Are Ranked Descendingly

\begin{tabular}{|c|c|c|c|c|c|}
\hline \multicolumn{6}{|c|}{ 1st Dimension: Teaching Strategies } \\
\hline Item No & Content & Mean & St Dev & Rank & Degree \\
\hline 1 & $\begin{array}{l}\text { Uses creative teaching methods such as } \\
\text { "brainstorming }\end{array}$ & 2.61 & 1.229 & 1 & moderate \\
\hline 2 & Trains students to debate, play roles "drama and acting & 2.58 & 1.105 & 2 & moderate \\
\hline 10 & $\begin{array}{l}\text { Students gain sensitivity to problems and work to } \\
\text { solve them }\end{array}$ & 2.56 & 1.174 & 3 & moderate \\
\hline 5 & $\begin{array}{l}\text { Helps students find appropriate responses to different } \\
\text { situations and ideas on a situation or problem }\end{array}$ & 2.48 & 1.236 & 4 & moderate \\
\hline 8 & $\begin{array}{l}\text { relies on modern methods of communicating } \\
\text { information as a search and survey method }\end{array}$ & 2.40 & 1.122 & 5 & moderate \\
\hline 9 & $\begin{array}{l}\text { Students' scientific sense is stimulated by using mental } \\
\text { maps and hierarchical networks }\end{array}$ & 2.36 & 1.093 & 6 & moderate \\
\hline 6 & Use lots of puzzles and educational games & 2.24 & 1.290 & 7 & low \\
\hline 12 & $\begin{array}{l}\text { Encourage students to think beyond thinking "thinking } \\
\text { thinking", }\end{array}$ & 2.23 & 1.478 & 8 & low \\
\hline 11 & Avoids the traditional teaching methods based on tests & 2.10 & 1.041 & 9 & low \\
\hline 7 & $\begin{array}{l}\text { The students are trained on the techniques of creativity } \\
\text { such as "defrag separarted pieces" }\end{array}$ & 2.05 & 0.855 & 10 & low \\
\hline 3 & $\begin{array}{l}\text { Ensures effective discussion as one way to stimulate } \\
\text { thinking }\end{array}$ & 2.04 & 0.977 & 11 & low \\
\hline \multirow[t]{2}{*}{4} & $\begin{array}{l}\text { Use techniques and multimedia that help exploit } \\
\text { mental potentials as much as possible }\end{array}$ & 1.86 & 0.803 & 12 & low \\
\hline & Dimension as a whole & 2.29 & 0.760 & & \\
\hline \multicolumn{6}{|c|}{$2^{\text {nd }}$ Dimension: Material Preparations } \\
\hline 42 & $\begin{array}{l}\text { Abundance of means and technologies of education: } \\
\text { computer, Internet, etc }\end{array}$ & 3.01 & 1.405 & 1 & moderate \\
\hline 40 & $\begin{array}{l}\text { Availability of high-readiness school facilities for } \\
\text { creative activities }\end{array}$ & 2.57 & 1.333 & 2 & moderate \\
\hline 43 & $\begin{array}{l}\text { Infrastructure available for creative activities: halls, } \\
\text { workshops, laboratory rooms, etc }\end{array}$ & 2.53 & 1.214 & 3 & moderate \\
\hline 41 & $\begin{array}{l}\text { Multiple sources of access to information and } \\
\text { accessibility }\end{array}$ & 2.37 & 1.131 & 4 & moderate \\
\hline 45 & $\begin{array}{l}\text { Enrichment of school libraries with modern books and } \\
\text { references }\end{array}$ & 2.33 & 2.082 & 5 & low \\
\hline \multirow[t]{2}{*}{44} & Allocate sufficient budget to finance creative projects & 2.02 & 1.195 & 6 & Low \\
\hline & Total Dimension & 2.47 & 0.861 & \multicolumn{2}{|l|}{ moderate } \\
\hline
\end{tabular}




\section{$3^{\text {rd }}$ Dimension: "extra-curricular activities}

28 Students encourage students to participate in literary contests "Poetry, Story, Essay"

26

27

24

30

23

31

32

29

25

21

22

4

Students are encouraged to search for information in the library or the Internet

27

Uses a guide to extracurricular activities and its
objectives

$$
\text { Assist students in the preparation of research and }
$$
studies related to the curriculum

0

Students are encouraged to hold exhibitions of plastic arts and photography

3

$$
\text { Provides a pleasant and loving extravagant activities }
$$
for students

1

Students are trained to perform television and film shows with animation, drawings, sound effects and colors.

2

$$
\begin{aligned}
& \text { Involves students in planning and preparing for } 2.3 \\
& \text { extracurricular activities }
\end{aligned}
$$

9 Students are trained to make decorative patterns and handicrafts.

5
There are material and moral incentives for 2.22 extracurricular activities

1
Provides students with a variety of renewable, varied

\begin{tabular}{|c|c|c|c|c|c|}
\hline \multicolumn{6}{|c|}{$4^{\text {th }}$ dimension: teacher's personal traits } \\
\hline 37 & He senses problems and tolerates ambiguity & 3.05 & 1.592 & 1 & moderate \\
\hline 35 & $\begin{array}{l}\text { Ensures a balance between competition and } \\
\text { cooperation }\end{array}$ & 3.00 & 1.689 & 2 & moderate \\
\hline 36 & $\begin{array}{l}\text { He works in team spirit and with the participation of } \\
\text { all relevant parties }\end{array}$ & 2.99 & 1.461 & 3 & moderate \\
\hline 33 & $\begin{array}{l}\text { Avoids stereotypical thinking and refuses to maintain } \\
\text { the status quo }\end{array}$ & 2.92 & 1.461 & 4 & moderate \\
\hline 39 & Openness and acceptance are practiced with students & 2.84 & 1.481 & 5 & moderate \\
\hline 34 & $\begin{array}{l}\text { Has high self-valididty and ability to take } \\
\text { responsibility }\end{array}$ & 2.47 & 1.455 & 6 & moderate \\
\hline \multirow[t]{2}{*}{38} & Tend to adventure and desire to challenge odds 38 & 2.45 & 1.222 & 7 & moderate \\
\hline & Total dimension & 2.82 & 1.119 & \multicolumn{2}{|l|}{ moderate } \\
\hline \multicolumn{6}{|c|}{$5^{\text {th }}$ dimension: assessment strategies } \\
\hline 14 & $\begin{array}{l}\text { In its evaluation, it seeks to shift from the cognitive } \\
\text { capacity test to the evaluation of multiple capacities, } \\
\text { from achieving efficiency to achieving quality and } \\
\text { excellence }\end{array}$ & 2.58 & 1.382 & 1 & moderate \\
\hline 15 & Adopts clear evaluation strategies, characterized by & 2.42 & 1.274 & 2 & moderate \\
\hline
\end{tabular} and adequate activities

2

$\begin{array}{lllll}\begin{array}{l}\text { Time is allocated for extracurricular activities that do } \\ \text { not conflict with students' time }\end{array} & 2.15 & 1.103 & 12 & \text { moderate } \\ \begin{array}{l}\text { Total dimension } \\ 2.40\end{array} & 0.877 & \text { moderate }\end{array}$


honesty, consistency, comprehensiveness and objectivity

17

Technology is used to innovate new methods of performance assessment

18

13

16

19

20
The Self-Assessment calendar encourages 2.27 self-assessment, Student Days, the Storybook

$\begin{aligned} & \text { Adopts accurate standards to evaluate student } \\ & \text { performance and apply it with high efficiency }\end{aligned}$
$\begin{aligned} & \text { Uses evaluation methods that focus on backward } \\ & \text { thinking }\end{aligned}$
$\begin{aligned} & \text { Give students enough time to think about answering } \\ & \text { the questions }\end{aligned}$
$\begin{aligned} & \text { Focuses on the strengths and weaknesses of students, } \\ & \text { and provides them with feedback in a friendly manner } \\ & \text { Total dimension }\end{aligned}$

Table (3) shows that the arithmetic means of the sample estimates for the study dimensions ranged between 2.41-2.82 and obtained a moderate score. The fourth dimension, "Personal Characteristics", ranked first with a mean of 2.82, and a standard deviation of (1.119), which represents a moderate rating, followed by the fifth dimension "assessment strategies" with a mean of 2.47 and a standard deviation of 861 . The " Extracurricular activities, " obtained a mean of 2.40, and standard deviation of (.877) with a moderate rating. The first dimension, "Teaching Strategies", obtained (2.60), and standard deviation (7.60), with a low rating. The second dimension, "Material Preparations", ranked the last with a mean of 2.21, a standard deviation of (.708) and a low rating score. The estimate of the sample members of the instrument as a whole was moderate, with a mean of 2.41 and a standard deviation of (.715).

This result can be attributed to the fact that the preparation of a creative learner must first find a creative teacher. The greatest burden is placed on the teacher, in order to enhance creativity. He is the one who resists isolation and alienation. He understands the importance of creative thinking identifies his student and strengthens the validity and the spirit of creativity of the learner, where the friendly atmosphere and courage of expression are the most important foundations of all practices and educational activities. This is in line with the findings of the study of Olayan (2010) and Khayo (2013

As shown in Table (3), item (37), "Sensitive to problems and tolerance of ambiguity", ranked first at the instrument level as a whole with a mean of 3.05 and a standard deviation of 1.592 . This result is attributed to the fact that the most important characteristic of creativity is novelty and authenticity, and this can be achieved only by tolerating the ambiguity and searching for the unfamiliar things to discover and make them familiar. Item (42) "The abundance of means and technologies of education: computer, was ranked second with a mean of 3.01 and a standard deviation of 1.405 , which represents a moderate rating. This result is attributed to the interest of Ministry of Education to provide the technical infrastructure through providing all schools in the country with computers equipped laboratories, connecting them to the internet, providing the trained and qualified human resources. Jordan will be an IT center to provide students with everything that is new and keep pace with scientific and cognitive progress of the world, which helps them scientific research, creativity and excellence.

Item 20, "focus on the strengths and weaknesses of students and provide them with feedback in a friendly manner", ranked last in the questionnaire level as a whole and represent a low rating with a mean of 1.382 and a standard deviation. 912). This result is attributed to the heavy burdens imposed on the teacher and the overcrowding of the students, which do not allow the teacher to draw up treatment plans to address and follow-up the weakness, forcing students to turn to resource halls that lack the necessary resources to address this weakness. This finding is in line with Diab (2005),

Similarly, item 44, "Allocation of an adequate budget for the funding of creative projects", obtained a mean of 2.02 and a standard deviation of 1.195. This result can be attributed to weak or zero financial funding for creative projects, because of difficult economic conditions, which has been reflected in the low percentage of expenditure on scientific 
research at the Arab level in general, and at the Jordanian level in particular. This is in line with Abu Shamaleh (2013).

Question 2: Is there a statistically significant difference at the level of significance $(\alpha \leq 0.05)$ in the sample of the study sample for the role of the teachers in creating an attractive environment for the development of creative thinking among the basic stage students according to gender, academic qualification and years of experience or their interaction?

In order to answer this question, the arithmetic means and standard deviations were calculated to estimate the role of the teachers in creating an attractive environment for the development of creative thinking among the basic stage students according to the study variables: gender, academic qualification and years of experience, as shown in Table 4.

Table 4. The Arithmetic Averages and the Standard Deviations of the Degree of Estimation of the Sample of the Study Sample Study Variables "Gender, Scientific Qualification, and Years of Experience" on the Instrument as a Whole

\begin{tabular}{lccl}
\hline variable & segment & mean & Stddev \\
\hline gender & male & 2.310 & 0.6517 \\
& female & 2.526 & 0.7662 \\
qualification & Bachelor or more & 2.488 & 0.69848 \\
& Less than bachelor & 2.300 & 0.7277 \\
Years of experience & $10 \mathrm{y}$ and more & 2.427 & 0.7312 \\
& Less than 10 y & 2.395 & 0.6984 \\
\hline
\end{tabular}

Table (4) shows that there are apparent differences in the arithmetic means and standard deviations of estimation degree by the sample members for the role of the teachers in creating an attractive environment for the development of creative thinking among the students of the basic stage of the study variables (gender, qualification and years of experience). These differences are statistically significant at the statistical significance level $(\boldsymbol{\alpha} \leq \mathbf{0 . 0 5})$, and use three-way ANOVA, as Table (5) shows this.

Table 5. Results of Three Way Anova that Indicates Differences in the Estimates of the Sample Members of the Study Attributed to the Variables "Gender, Academic Qualification, Years of Experience"

\begin{tabular}{|c|c|c|c|c|c|c|}
\hline $\begin{array}{l}\text { Source of } \\
\text { variance }\end{array}$ & $\begin{array}{l}\text { Sum } \\
\text { squares }\end{array}$ & of & $\begin{array}{c}\text { Deg of } \\
\text { freedom }\end{array}$ & $\begin{array}{c}\text { Mean of } \\
\text { squares }\end{array}$ & F value & Significance \\
\hline gender & 2.721 & & 1 & 2.721 & 5.455 & .020 \\
\hline experience & 0.013 & & 1 & 0.013 & 0.026 & .871 \\
\hline qualification & 2.022 & & 1 & 2.022 & 4.054 & 0.45 \\
\hline total & 899.24 & & 300 & & & \\
\hline
\end{tabular}

Table (5) shows statistically significant differences in the estimates of the study sample for the role of teachers in creating an attractive environment for the development of creative thinking among the students of the basic stage, attributed to the gender and academic qualification. The value of $(\mathrm{F})$ for gender was 5.455 at significance level of (.02), for the favor of female teachers. The value of (F) for the variable "academic qualification" was (4.054) at the level of significance of (.045), to the favor of teachers holding bachelor degree or more. There are no significant differences in the estimates of the study sample of the role of teachers in creating an attractive environment. This can be explained by the fact that female teachers have the ability to create an attractive environment for the development of creative thinking among students more than male teachers, because they have a personal characteristic that is dominated by maternal emotion, which is the art of acceptance of students in the first day of their school entrance, which now eases the shock of separation from mother; because the Ministry of Education in Jordan pay attention to the lower basic stage, as the female teachers teach this class as an extension of the family, the same time it constitutes the student's starting point in the educational hierarchy and consolidate the pattern of creative innovative thinking they have.

This result is also attributed to the fact that highly qualified teachers have the ability to develop their students' thinking, because of the nature of study plans of their graduate studies that consist of a variety of courses on thinking and strategies. This is consistent with the findings of the study of Alassaf (2013) and Albelushi (2010) 


\section{Conclusion}

The study concluded that teachers for developing attractive environment for Creative Thinking were mid regardless of their gender and academic qualifications procedural.

\section{Recommendations}

Based on the study findings the researcher recommends the following

- Review programs for the preparation and training of teachers, and the need to emphasize the inclusion of strategies for the development of creative thinking, and methods of development of students in the plans.

- Reinforcement of the school curriculum for the basic stage of creative thinking programs, and the use of modern teaching and assessment strategies.

- $\quad$ Pay attention to improving the classroom and school environment, and moving from a thinking hindering environment to a stimulating environment of thinking.

- Support extra-curricular activities and provide the necessary material resources to implement them.

- Conduct dimension studies on this subject that target other educational stages.

- $\quad$ Establish a variety of model institutions that foster creativity and innovators in various fields.

- Strengthening cooperation and coordination between educational institutions and community institutions is an urgent need to create an environment conducive to creativity. Creativity is not an individual act, but a human trait in a permanent interactive movement.

- To provide teachers with the latest developments in the educational arena of research and studies on improving the educational process, which helps institutionalize creativity as a behavior and methodology of teachers and their students at the same time.

\section{References}

Abdulhaq, Zuhriya \& Alojaili, Sabah. (2015). Brain control and its relation to creative thinking among university students in Jordan in the light of some demographic variables. Jordan Journal of Educational Sciences, 8(2), 119-130.

Abu Alsaud, Saeed. (2010). Prepare the teacher and face the challenges of the future. Educational and Psychological studies. Journal of Faculty of Education, Zagazig, 1(67), 23-95.

Abu Jado, Saleh \& Nofal, Mohammed. (2007). Teaching Thinking - Theory and Practice (1st Ed.). Amman: Dar Al Masirah for Printing, Publishing and Distribution.

Abu Shairah, Khalid, Ishtiwi, Fawzi, Ghabari, \& Thaer. (2010). Implications of Implementing a Realistic Assessment System for Students in the First Four Levels of basic Education in Zarqa Governorate. Al-Najah Journal of Human Sciences, 754-797.

Abu Shamaleh \& Faraj Ibrahim. (2013). The role of school administration in the development of creativity among teachers of public education in Gaza governorates from their point of view, research paper - Fifth Annual Conference (Development of Culture of Creativity) organized by the Ministry of Culture / Palestinian National Authority.

Alaga, Hani. (2014). The role of secondary education institutions in developing the creativity of its students and envisages a proposal to activate it. Unpublished MA, University of Jordan, Jordan.

Alassaf, Jamal Abdel Fattah. (2013). Attitudes of Social Studies Teachers toward Developing Creative Thinking Skills among the Students of the Basic Stage in the Third Directorate of Education of Oman. The Islamic University of Educational and Psychological Studies, 21(1), 269-29.

Alazzam, Emad Faisal. (2017). Attitudes of teachers towards the use of modern teaching strategies in Irbid Governorate. Al-Quds Open University for Research and Educational and Psychological Studies, 6(20), 153-163.

Albasheer, Akram \& Essam, Areej. (2011). Use of alternative assessment strategies and instruments in evaluating mathematics and Arabic language learning in Jordan, Hashemite university Faculty of Educational sciences Dept. of Curricula and Instruction. Retrieved from https://eis.hu.edu.jo/deanshipfiles/pub103762158.pdf 
Albelushi, Maryam BintSulaiman. (2010). The reality of practicing Islamic education teachers methods of developing creative thinking skills in teaching students of the second cycle of basic education in the Sultanate of Oman. Unpublished MA, Mutah University, Jordan.

Ali, Mohamed El Sayed. (2011). Modern trends and applications in curricula and teaching methods (1st ed.). Amman: Dar Al Masirah.

Al-Nafie'i, Nasser bin Qatim. (2010). The extent to which science teachers practice some creative thinking development skills among middle school students. Unpublished Master Thesis, Imam Muhammad Bin Saud Islamic University, Riyadh, Saudi Arabia.

Alotoum, Adnan et al. (2007). Development of thinking skills - Theoretical models and practical applications (1 $1^{\text {sted.). }}$. Dar Almaseerah, Amman.

Alqarar'ah, Ahmad. (2014). The Effect of Brainstorming in the Teaching of Science on the development of creative thinking skills among the $7^{\text {th }}$ grade students in Tafilah Schools. Journal of Alnajah University for Research(Humanities), 28(4), 669-705.

Alshalti, Amal Mohammad. (2010). The Impact of the School Environment System on the Development of Creative Values in fine art in Secondary Education from the Point of View of Teachers, Unpublished Master Thesis, Umm Al-Qura University, Saudi Arabia

Alsorour, Nadia. (2002). Introduction to Creativity (1st ed.). Amman: Dar Wael Publishing.

Alswaiti, Abdel Nasser. (2015). The role of the school administration in developing creativity in the public schools in Hebron and Bethlehem governorates and its obstacles from the point of view of it principals. Journal of the Faculty of Basic Education for Educational and Human Sciences, University of Babylon, 1(22), 27-50.

Altarawneh, Mohammad. (2011). A Proposed Model for Quality Assurance Criteria for Real Student Assessment in Educational Curricula, Research Presented at the Arab International Conference for Quality Assurance of Higher Education, Zarqa Private University, Jordan, 10-12 / 5/2011.

Barakat \& Abdul-Jabbar. (2017). The impact of teaching Arabic language using cloud computing technology in developing the self-learning and creative thinking skills of the third grade students in private schools in Jordan. Journal of Educational Sciences and Psychology-Islamic University in Gaza, 25(4), 544-570.

Chin, Y. (2013). The relationship between undergraduate students' creative self efficiency, creative ability and career self-management. International Journal of Academic Research in Progressive Education and Development, 2(2), 181-193.

DeBono Center for Teaching Thinking (2015). Introduction to Teaching Thinking and Development of Creativity, (2015) (1st ed.). Amman: DeBono Learning Center.

Diab, SuhailRizk. (2005). Obstacles against the development of creativity among the students of the basic stage in schools in the Gaza Strip. Presented to the second conference of the Faculty of Education - Islamic University of Gaza

Hecerian, B.Sc. (2004). The effects of six thinking method on effective learning in biology the fifth international conference on creative thinking, university of Malta.

Jahjah. (2016). Effect of the six hats method in developing the skills of creative thinking, decision-making and social studies (semi-experimental study of third grade students in Lattakia), MA, Tishreen University, Faculty of Education, Syrian Arab Republic.

Jarwan, Fat-hi Abdel Rahman. (2012). Creativity: concept, standards, components, theories, characteristics, stages, measurement, and training (1st ed.). Amman: Dar Al Fikr for Printing, Publishing and Distribution.

Jarwan, Fat-hi Abdel Rahman. (2013). The approaches for discovering Talented Individuals (4th ed.). Amman: Dar Al Fikr for Printing, Publishing and Distribution

Khadr, Fakhri Rashid (2015). The impact of applying enrichment activities in the development of creative thinking skills among $8^{\text {th }}$ grade students in geography. SDirasat, Educational Sciences, 42(3), 873-890.

Khayo, Ro'yaNawaf. (2013). The roles and competences of the teacher in the twenty-first century from the point of view of faculty members in the Faculty of Education. University of Damascus Journal, 29(1), 525-565.

Ma'alouli, Raymond. (2010). Quality of the material environment of the school and its relation to environmental activities (survey - dimension study in the basic education schools - Damascus). University of Damascus 
Journal, $26(2+1), 97-136$.

Mansour, Mirna (2013). The role of the educational staff in developing creative thinking among the children of kindergartens from the point of view of teachers. University of Damascus Journal, 29(1), 52-548.

Ministry of Education, Jordan. (2010). The project to develop learning towards knowledge economy for the second phase (ERfKE II). Teacher's Message, 48(1), 112-122.

Mostafa, Nimer Mustafa. (2011). Improving thinking skills (1st ed.). Amman: Albedayah publishers and distributors.

Nofal, Muhammad Bakr. (2008). Practical applications in the development of thinking using habits of mind (1st ed.). Dar Almasirah, Amman.

Nour, Kathem. (2015). Thinking and creativity in kindergarten, school and university (2nd ed.). Amman: Dar Debono Publishing and Distribution.

Olayan, Yasmine Nayef. (2010). Characteristics of teachers as perceived by students of the Basic stage, and its relation to innovative activities, unpublished master thesis, Al-Azhar University, Gaza, Palestine.

Oudah, Ahmed Sulaiman. (2010). Measurement and evaluation in the process (4th ed.). Irbid: Dar Alamal.

Qasim, Intisar Kamal. (2014). The school environment and its relation to the cognitive motivation and reflective thinking of the university students. Journal of the College of Education for Girls, 25(3), 597-636.

Qatami, Youssef. (2012). Teaching strategies (1st ed.). DarAmmar, Amman

Ranko, Mark. (2012). Creativity: theories and subjects. Translation by ShafiqAlawneh. Riyadh: Obeikan bookshop.

Robinson, Keane. (2009). Mind Industry - The role of culture and education in shaping your creative mind. Translation - Rama Moussalli (1st ed.). Amman: National Library Department.

Roney, Kathleen. (2000). Characteristics of effective middle level teachers: A case study of principal, teacher, and student perspectives. Unpublished Doctoral Dissertation, Temple University, Philadelphia, PA.

Sa'adah, Jawdat. (2003). Teaching Thinking Skills with Hundreds of Applied Examples (1st ed.). Amman: Dar Al Shorouk.

Salloum, Mona Mohamed. (2014). The impact of the program of office activities to develop some creative abilities in the performance of language of kindergarten children. Journal of Educational and Psychological Research, $1(43), 218-241$.

Tawalbah, Aisha. (2012). The difference between teachers' awareness of their self-efficacy in developing their students' creativity and awareness. Jordanian Journal of Educational Sciences, 8(2), 119-130.

Yagoob, M. (2012). Developing creative thinking: using a cognitive teaching model in literature classroom. The Journal of Learning, 18(6), 71-82. 